\title{
SITUAÇÃO ATUAL DA FLUORETAÇÃO DE ÁGUAS DE ABASTECIMENTO PÜBLICO NO ESTADO DE SÃO PAULO — BRASIL
}

Osvaldo C. Buendia *

BUENDIA, O. C. Situação atual da fluoretação de águas de abastecimento público no Estado de são Paulo - Brasil. Rev. Saúde públ., S. Paulo, 17:226-32, 1983.

RESUMO: Destacando alguns fatos relacionados com a evolução da fluoretação de águas no Estado de São Paulo (Brasil), foram citadas Leis, Decretos e Portarias que amparam a incrementação do método. Foram citados os órgãos públicos que vêm dando assiștência à implantação de sistemas de fluoretação, posicionando a ação desenฬolvida por eles, cuja cobertura é de $25,39 \%$ do total dos municípios. Foram relacionadas nominalmente as 1.45 cidades com água fluoretada até o momento, com o composto utilizado, o órgão que implantou o sistema, a população beneficiada e o custo/hab./ano.

UNITERMos: Agua. Fluoração. São Paulo, Brasil.

\section{INTRODUÇÃO}

Baseada nos resultados obtidos na redução da incidência da cárie dentária através dos estudos realizados nos EUA com fluoretação agregada de águas de abastecimento público, durante 8 anos, a Fundação Serviços de Saúde Pública (FSESP) implantou o primeiro sistema no Brasil na cidade de Baixo Guandu, Espírito Santo, em 1953 (Grinplastch) ${ }^{4}$.

O pioneirismo da FSESP e a eficácia obtida nos EUA estimularam o país a adotar o método na prevenção da cárie dentária.

Após várias reuniões de estudos, o município de Marilia teve suas águas fluoretadas em $12 / 12 / 56^{* *}$, sendo a primeira cidade do Estado de São Paulo a receber o benefício.

Nesse mesmo ano foi apresentado, na Assembléia Legislativa do Estado, o Projẹto de Lei $n^{\circ} 427$, de $17 / 7 / 56^{8}$, dispondo sobre autorização ao Departamento de Águas e Esgotos para adicionar flúor às águas de abastecimento público, inclusive do município de São Paulo. O Projeto de Lei foi aprovado, mas o Governador vetou-o. Novamente foi colocado em discussão e, baseado em argumentações apresentadas por Viegas ${ }^{11}$ sobre as vantagens da fluoretação de águas, o veto foi rejeitado. A Assembléia Legislativa promulgou, então a Lei no $4.687 \mathrm{em} 18 / 4 / 58^{5}$, autorizando o referido órgão a compri-lo, fato que não aconteceu e, até o momento, o município de São Paulo continua sem o benefício.

Lentamente, com o decorrer dos anos, o método foi sendo adotado por algumas cidades do Estado, através da própria municipalidade.

\footnotetext{
* Da Coordenação Geral do Programa de Prevenção da Cárie Dentária do Departamento de Assistência ao Escolar da Secretaria de Estado da Educação - Rua Piratininga, 85 - 03042 São Paulo, SP - Brasil.

* Comunicação pessoal do Departamento de Aguas e Esgotos de Marilia.
} 
BUENDIA, O.C. Situaçăo atual da fluoretaçăo de águas de abastecimento público no Estado de Sáo Paulo - Brasil. Rev. Saúde públ., S. Paulo, 17:226-32, 1883.

Em 1974, é promulgada a Lei Federal $\mathrm{n}^{\circ} 6.050^{\circ}$ a qual, em 1975 , é regulamentada pelo Decreto no $76.872^{2}$, expressando a obrigatoriedade da fluoretação de águas no Brasil.

Em 1977, o Governo do Estado promulga o Decreto n' $10.330^{1}$ no qual, entre outras coisas, proporciona financiamento aos municipios interessados em instalar sistemas de fluoretação de águas de abastecimento público.

A partir desse ano, a Companhia de Saneamento Básico do Estado de São Paulo (SABESP) inicia seu programa de fluoretação de águas com a utilização do ácido fluossilícico, produto resultante da fabricação de fertilizantes, de baixo custo, e consonante com a Portaria do Ministério da Saúde no $635 / B s b$ de $1975^{7}$ que determina normas e padrões a serem seguidos na adoção do método. $O$ primeiro município a ter suas águas fluoretadas com o composto citado foi Registro, em 28/02/77*.

No mesmo ano, 1977, o Departamento de Assistência ao Escolar (DAE) da Secretaria de Estado da Educaçăo injicia, também, um programa de assistência aos municípios interessados em fluoretar suas águas, colaborando com a incrementação do método.

Em 1979, a Secretaria de Estado da Saúde 9,10 (SAƯDE), por meio das Resoluçōes SS-67 e SS s/no de 29/08/79 e 26/09/79, respectivamente, constitui grupo de trabalho a fim de estudar e propor medidas visando a implantação de sistemas de fuoretação nos municipios do Estado de São Paulo. Composto de representantes da SAúDE, da SABESP, da Companhia de Tecnologia de Saneamento Ambiental (CETESB), da Faculdade de Saúde Pública da USP e do DAE, o grupo concluiu com medidas que proporcionaram um convênio entre a SAÚDE e CETESB, o qual vem intensificando a implantação de sistemas de fluoretação de águas através da doação de equipamentos, material de laboratório e ácido fluossilícico. 0 mesmo processo foi seguido pelo DAE e a SABESP continuou com o seu programa já em desenvolvimento.

\section{SITUACXO ATUAL}

Em 1977, o Estado de São Paulo tinha cerca de 19 municipios com água fluoretada.

Pela ação proporcionada pelos três órgãos públicos citados, o método vem sendo incrementado de maneira significativa, de modo a contarmos, no momento, com 145 municípios com água fluoretada, correspondendo a $25,39 \%$ do total dos municipios do Estado, beneficiando 5.890 .152 habitantes da zona urbana, Fundação IBGE 3 , que representam $26,18 \%$ do seu total.

A Tabela 1, relaciona os órgãos responsáveis pela implantação dos sistemas de fluoretação existentes no Estado de São Paulo com os compostos aplicados, evidenciando o número de municípios beneficiados, mostrando que o órgão que mais tem contribuido para a incrementação do método é a SABESP e que o composto mais utilizado tem sido o ácido fluossilícico.

\footnotetext{
* Comunicação pessoal com "o Departamento de Controle Santtário da SABESP.
} 
BUENDIA, O.C. Situação atual da fluoretação de ágtas de abastecimento público no Estado de São Paulo - Brasil. Rev. Saúde públ., S. Paulo, 17:226-32, 1983.

T A B E I A 1

Distribuição dos municípios com água fluoretada, segundo os órgãos responsáveis pela implantação e os compostos usados. São Pa $\cdots$ lo, 1982.

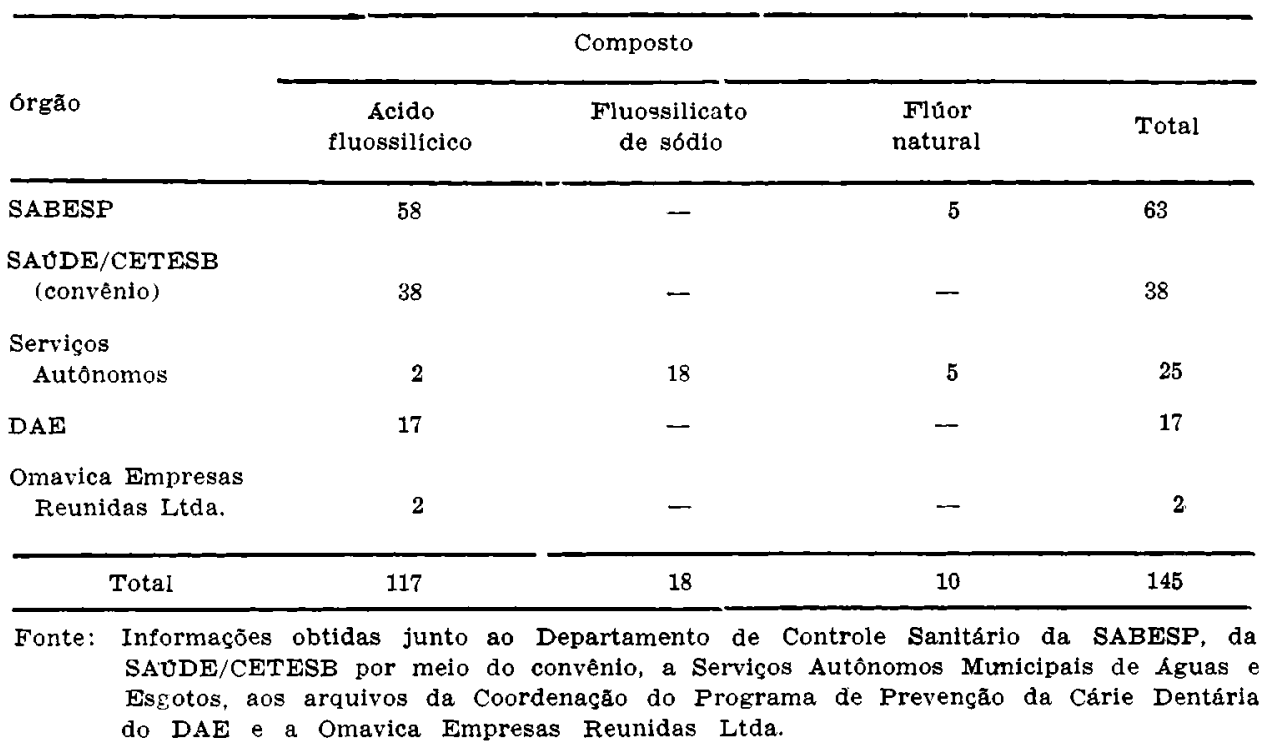

Análises de custos de compostos demonstram que o custo atual da fluoretação de águas é de Cr\$ 10,95/hab./ano com a utilização do ácido fluossilícico e de Cr\$ $18,25 / \mathrm{hab}$./ano com a do fluossilicato de sódio.

N

1 - Adamantina
2 - Águas de Lindóia
3 - Américo Brasiliense
4 - Amparo
5 - Analândia
6 - Aparecida
7 - Apiai
8 - Araçatuba
9 - Araras
10 - Araraquara
11 - Ariranha
12 - Assis
13 - Atibaia
14 - Avaré
15 - Bady Bassit

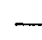

Nominalmente, conforme o composto utilizado, o órgão responsável pcla implantação e à população beneficiada, temos a seguinte sitụação atual:

Composto

Órgão

População

ácido

- SABESP

24.597

- ácido

- SAÚDE/CETESB

9.245

- ácido

- DAE

9.933

- ácido

- SAÚDE/CETESB

29.250

- ácido

- SAÚDE/CETESB

1.087

- ácido - SAÚDE/CETESB

28.876

- ácido - SABESP

- sal - Autônomo

12.128

118.666

55.836

- ácido - SAÚDE7CETESB

120.733

- sal

- Autônomo

3.617

62.377

49.178

41.468

1.101 
BUENDIA, O.C. Situaçăo atual da fluoretaçăo de águas de abastecimento público no Estado de Säo Paulo - Brasil. Rev. Saúde públ., S. Paulo, 17:226-32, 1983.

\begin{tabular}{|c|c|c|c|c|}
\hline Cidade & & Composto & Órgão & População \\
\hline 16 - Barbosa & $\ldots$ & natural & - Autônomo & 3.446 \\
\hline 17 - Bariri & - & ácido & - SAÚDE/CETESB & 15.519 \\
\hline 18 - Barretos & - & ácido & - Autônomo & 67.649 \\
\hline 19 - Barueri & - & ácido & - SABESP & 75.775 \\
\hline 20 - Batatais & - & ácido & - DAE & 30.742 \\
\hline 21 - Bauru & - & sal & -- Autônomo & 184.200 \\
\hline $22-$ Birigüi & - & ácido & — SAÚDE7CETESB & 46.063 \\
\hline 23 - Boa Esperança do Sul & $-\ldots$ & ácido & - SAÚDE7CETESB & 4.887 \\
\hline $24-$ Botucatu & - & ácido & - SABESP & 59.989 \\
\hline 25 - Bragança Paulista & - & ácido & - SABESP & 63.541 \\
\hline $26-$ Brotas & - & ácido & - SAÚDE/CETESB & 7.620 \\
\hline 27 - Cachoeira Paulista & - & ácido & - SABESP & 16.830 \\
\hline 28 - Caconde & - & ácido & $-\mathrm{DAE}$ & 8.277 \\
\hline 29 - Cajatí (Dist. Jacupiranga) & - & ácido & - SABESP & 10.269 \\
\hline 30 - Cajuru & - & ácido & - SABESP & 7.604 \\
\hline 31 - Campinas & - & sal & - Autônomo & 607.638 \\
\hline 32 - Caçapava & - & ácido & - SABESP & 45.680 \\
\hline 33 - Campos do Jordão & - & ácido & - SABESP & 25.174 \\
\hline 34 - Capão Bonito & - & ácido & - SABESP & 25.429 \\
\hline 35 - Carapicuíba & - & ácido & - SABESP & 187.358 \\
\hline $36-$ Cedral & - & ácido & — SAÚDE/CETESB & 2.402 \\
\hline 37 - Cerquilho & - & ácido & - DAE & 10.422 \\
\hline 38 - Conchas & - & ácido & - SAÚDE/CETESB & 7.220 \\
\hline 39 - Cosmorama & - & ácido & — SAÚDE/CETESB & 2.725 \\
\hline 40 - Cravinhos & - & ácido & — SAÚDE/CETESB & 13.974 \\
\hline 41 - Espirito Santo do Pinhal & - & ácido & - SABESP & 23.793 \\
\hline 42 - Eldorado & - & ácido & - SABESP & 3.685 \\
\hline 43 - Franca & - & ácido & - SABESP & 145.034 \\
\hline 44 - Gália & - & ácido & - DAE & 4.575 \\
\hline 45 - Garça & - & ácido & - SAÚDE/CETESB & 27.860 \\
\hline 46 - Guaíra & - & sa! & - Autônomo & 19.199 \\
\hline 47 - Guapiaçu & - & ácido & - SAÚDE/CETESB & 3.422 \\
\hline 48 - Guapiara & - & ácido & - SABESP & 3.365 \\
\hline 49 - Guararapes & - & ácido & - DAE & 17.786 \\
\hline 50 - Guararema & - & ácido & - SABESP & 7.042 \\
\hline 51 - Guaratinguetá & - & ácido & - Autônomo & 74.130 \\
\hline 52 - Herculândia & - & ácido & — SAÚDE7CETESB & 3.900 \\
\hline 53 - Ibaté & - & ácido & - SAÚDE/CETESB & 8.549 \\
\hline 54 - Ibirá & - & ácido & - SABESP & 5.540 \\
\hline 55 - Ibitinga & - & ácido & - DAE & 23.547 \\
\hline 56 - Ibiúna & - & ácido & - SABESP & 19. 196 \\
\hline 57 - Igaratá & - & ácido & - SABESP & 2.216 \\
\hline 58 - Iguape & - & ácido & - SABESP & 16.523 \\
\hline 59 - Indaiatuba & - & sal & - Autônomo & 49.059 \\
\hline $60-$ Itajobi & - & ácido & - SAÜDE/CETESB & 6.064 \\
\hline 61 - Itapetininga & - & ácido & - SABESP & 64.147 \\
\hline 62 - Itapeva & - & ácido & - SABESP & 38.857 \\
\hline 63 - Itapevi & - & ácido & - SABESP & 53.819 \\
\hline
\end{tabular}


BUENDIA, O.C. Situaçáo atual da fluoretaçăo de águas de abastecimento público no Estado de São Paulo - Brasil. Rev. Saúde pübl., S. Paulo, 17:226-32, 1983.

\begin{tabular}{|c|c|c|c|c|}
\hline Cidade & & Compostc & Orgão & População \\
\hline 64 - Itatiba & - & ácido & - SABESP & 35.960 \\
\hline 65 - Itirapuã & - & ácido & - SABESP & 2.900 \\
\hline 66 - Jacareí & - & ácido & - DAE & 108.665 \\
\hline 67 - Jacupiranga & - & ácido & - SABESP & 7.076 \\
\hline 68 - Jandira & - & ácido & - SABESP & 36.267 \\
\hline 69 - Joanópolis & - & ácido & - SABESB & 3.336 \\
\hline $70-$ Jundiai & - & ácido & — SAÚDE7CETESB & 224.717 \\
\hline $71-$ Juquiá & - & ácido & - SABESP & 7.958 \\
\hline 72 - Lins & - & natural & - SABESP & 46.901 \\
\hline 73 - Lucélia & - & ácido & - SABESP & 11.748 \\
\hline 74 - Luisiânia & - & natural & - SABESP & 2.527 \\
\hline 75 - Macatuba & - & ácido & - SABESP & 6.392 \\
\hline 76 - Mairiporã & - & ácido & - SABESP & 19.203 \\
\hline 77 - Marilia & - & sal & - Autônoma & 110.209 \\
\hline 78 - Mendonça & - & ácido & - SAŨDE/CETESB & 1.297 \\
\hline 79 - Meridiano & - & ácido & - SAƯDE/CETESB & 1.479 \\
\hline $80-$ Mirassol & - & ácido & - SAƯDE/CETESB & 25.877 \\
\hline 81 - Mogi Guaçu & - & sal & - Autônomo & 65.810 \\
\hline 82 - Monte Aprazivel & - & ácido & - SABESP & 10.578 \\
\hline 83 - Nazaré Paulista & - & ácido & - SABESP & 2.485 \\
\hline 84 - Nhandeara & - & ácido & - SABESP & 5.984 \\
\hline 85 - Nova Europa & - & ácido & - DAE & 2.039 \\
\hline 86 - Novo Horizonte & - & ácido & - SABESP & 18.885 \\
\hline 87 - Nova Odessa & - & sal & - Autônomo & 19.622 \\
\hline 88 - Olímpia & - & ácido & - SAÜDE/CETESB & 25.502 \\
\hline 89 - Orlândia & - & ácido & - SAÚDE/CETESB & 25.495 \\
\hline 90 - Ourinhos & - & ácido & - SAÚDE/CETESB & 53.674 \\
\hline 91 - Palmital & - & ácido & — SAƯDE/CETESB & 11.100 \\
\hline 92 - Paraguaçu Paulista & - & natural & - Autônomo & 18.398 \\
\hline 93 - Paraiso & - & ácido & - SAƯDE/CETESB & 1.745 \\
\hline 94 - Paulínia & - & ácido & - SABESP & 19.283 \\
\hline 95 - Paulo de Faria & - & ácido & - SABESP & 5.025 \\
\hline 96 - Pederneiras & - & ácido & - SABESP & 20.193 \\
\hline 97 - Pedregulho & - & ácido & - SABESP & 6.543 \\
\hline 98 - Pedreira & - & ácido & - SAƯDE/CETESB & 19.792 \\
\hline 99 - Penápolis & - & ácido & - DAE & 32.655 \\
\hline 100 - Pereiras & - & natural & - Autônomo & 1.588 \\
\hline 101 - Pindamonhangaba & - & ácido & - SABESP & 63.624 \\
\hline 102 - Piracaia & - & ácido & - SABESP & 7.623 \\
\hline 103 - Piracicaba & -- & sal & - Autônomo & 202.217 \\
\hline 104 - Piraju & - & ácido & - SABESP & 16.664 \\
\hline 105 - Pirassununga & - & ácido & - SAÚDE7CETESB & 36.833 \\
\hline 106 - Piratininga & - & ácido & - SABESP & 5.898 \\
\hline 107 - Porto Feliz & - & ácido & - DAE & 19.879 \\
\hline 108 - Porto Ferreira & - & ácido & - DAE & 25.889 \\
\hline 109 - Pradópolis & - & sal & - Autônomo & 6.204 \\
\hline 110 -- Presidente Prudente & - & natural & - SABESP & : 133.510 \\
\hline
\end{tabular}


BUENDIA, O.C. Situaçăo atual da fluoretaçăo de águas de abastecimento público no Estado de Săo Paulo - Brasil. Rev. Saúde públ., S. Paulo, 17:226-32, 1983.

\begin{tabular}{|c|c|c|c|c|}
\hline Cidade & & Composto & Orgão & População \\
\hline 111 - Presidente Venceslau & - & ácido & $-\mathrm{DAE}$ & 27.225 \\
\hline 112 - Promissão & - & ácido & — SAÚDE7CETESB & 15.791 \\
\hline 113 - Registro & - & ácido & - SABESP & 29.125 \\
\hline 114 - Ribeirão Branco & - & ácido & - SABESP & 2.036 \\
\hline 115 - Ribeirão Pires & - & ácido & - SABESP & 57.210 \\
\hline 116 - Rio Grande da Serra & - & ácido & - SABESP & 20.215 \\
\hline 117 - Rio das Pedras & -- & ácido & - DAE & 10.634 \\
\hline 118 - Santa Bárbara D’Oeste & 一 & sal & - Autônomo & 72.532 \\
\hline 119 - Santa Cruz das Palmeiras & - & ácido & - DAE & 12.895 \\
\hline 120 - Santa Cruz do Rio Pardo & - & ácido - & - SABESP & 22.793 \\
\hline 121 - Santa Fé do Sul & - & sal & - Autônomo & 17.536 \\
\hline 122 - Santa Izabel & 一 & sal & - Autônomo & 18.517 \\
\hline 123 - Santa Rita D' Oeste & - & natural & - Autônomo & 1.471 \\
\hline 124 - Santa Rosa do Viterbo & - & ácido & - SABESP & 11.666 \\
\hline 125 - São Bento do Sapucai & - & ácido & - SABESP & 3.732 \\
\hline 126 - São Carlos & - & sal & - Autônomo & 112.642 \\
\hline 127 - São José dos Campos & - & ácido & - SABESP & 281.361 \\
\hline 128 - São José do Rio Preto & - & ácido & - SAÚDE/CETESB & 183.471 \\
\hline 129 - São João da Boa Vista & -- & ácido & - SABESP & 46.123 \\
\hline 130 - São João do Pau D'Alho & - & natural & - Autônomo & 1.161 \\
\hline 131 - São Joaquim da Barra & - & ácido & — SAÚDE/CETESB & 26.670 \\
\hline 132 - São Manuel & 一 & ácido & - SABESP & 19.604 \\
\hline 133 - Serra Negra & - & ácido & — SAÚDE/CETESB & 13.929 \\
\hline 134 - Sete Barras & - & ácido & - SABESP & 3.481 \\
\hline 135 - Socorro & - & ácido & $-\mathrm{DAE}$ & 12.301 \\
\hline 136 - Sorocaba & - & sal & - Autônomo & 270.743 \\
\hline 137 - Taguaí & - & natural & - SABESP & 2.961 \\
\hline 138 - Taquaritinga & - & ácido & - OMAVICA & 28.210 \\
\hline 139 - Tatui & - & ácido & - SABESP & 45.607 \\
\hline 140 - Taubaté & - & ácido & - OMAVICA & 163.903 \\
\hline 141 - Tietê & & sal & - Autônomo & 15.825 \\
\hline 142 - Urupês & - & ácido & - SAÚDE/CETESB & 6.321 \\
\hline 143 - Valinhos & - & ácido & - DAE & 37.894 \\
\hline 144 - Valparaíso & - & sal & - Autônomo & 10.186 \\
\hline 145 - Vinhedo & - & ácido & - SAÜDE/CETESB & 21.299 \\
\hline
\end{tabular}

\section{Convençōes}

ácido : Ácido Fluossilicico sal : Fluossilicato de Sódio natural: Flúor natural 
BUENDIA, O.C. Situação atual da fluoretação de águas de abastecimento público no Estado de São Paulo - Brasil. Rev. Saúde públ., S. Paulo, 17:226-32, 1983.

BUENDIA, O. C. [The present position on fluoridation of water for human consumption in S. Paulo State, Brazil]. Rev. Saúde públ., S. Paulo, 17:226-32, 1983.

ABSTRACT: With a view to bringing out some facts connected with the progress achieved in water fluoridation in the State of $\mathbf{S}$. Paulo, Brazil, the paper quotes laws, decrees and other legal acts which form the basis for the spread of the method. The public agencies which are assisting in the implantation of fluoridation systems, are qucted and the action, covering $23.39 \%$ of all communities, which has been taken by them is discribed. The list of 145 communities fluoridated up to the present, the composite used, the implanting agency, the population benefited and cost/individual/year, are presented.

UNITERMS: Water. Fluoridation. S. Paulo, Brazil.

\section{REFERENCIAS BIBLIOGRÁFICAS}

1. DECRETO no 10.330 de $13 / 09 / 77$. Diario Oficial do Estado, 14 set. 1977. p. 14.

2. DECRETO n4 76.872 de 22/12/75. In: Ministério da Saúde. Legislaçáa federal do setor saúde. Brasilia, 1976. p. 6-7.

3. FUNDAÇÃO IBGE. Sinopse preliminar do censo demografico: São Paulo, Rio de Janeiro, 1981, v.1, t.1. (IX Recenseamento Geral do Brasil, 1980).

4. GRINPLASTCH, B.S. Fluoretação de águas no Brasil. [Apresentado ao $7 \circ$ Congresso Brasileiro de Engenharia Sanitária, Salvador, 1973]

5. LEI ne 4.687 de 18/04/58. Diário oficial do Estado, 19 abr, 1958.

6. LEI $n^{9} 6.050$ de 24/05/74. In: Ministério da Saúde. Legislação féderal do setor saúde. Brasilia, 1976. p. 5 .
7. PORTARIA ne $635 /$ Bsb de $26 / 12 / 75$. In: Ministério da Saúde. Legislaça federal do setor saúde. Brasilía, 1976. p. 8-24.

8. PROJETO de Lei no 427 de $17 / 07 / 56$. Difirio Oficial do Estado, 18 jul. 1956.

9. SECRETARIA DE ESTADO DA SAÚDE. Resolução SS-67 de 29/08/79, Dírrio Oficial do Estado, 30 ago. 1979. p. 42.

10. SECRETARIA DE ESTADO DA SAƯdE. Resolução SS-s/n' đe 26/09/79. Diário Oficial do Estado, 27 set. 1979, p. 48.

11. VIEGAS, A.R. Fluoretação das águas de abastecimento público. Rev. Ass. paul. cirurg. Dent., 12:57-66, 1958.

Reecebido para publicąão em 04/02/1983

Aprovado para publicaçāo em 15/03/1983 